\title{
Short-term changes in chlorophyll distribution in response to a moving storm: a modelling study
}

\author{
Yongsheng Wu ${ }^{1, *}$, Trevor Platt ${ }^{1}$, Charles C. L. Tang ${ }^{1}$, Shubha Sathyendranath ${ }^{1,2}$ \\ ${ }^{1}$ Coastal Ocean Science, Bedford Institute of Oceanography, Dartmouth, Nova Scotia B2Y 4A2, Canada \\ ${ }^{2}$ Plymouth Marine Laboratory, Prospect Place, The Hoe, Plymouth PL1 3DH, UK
}

\begin{abstract}
Using a 3-D ocean circulation model of the Labrador Sea, we investigated the immediate response, through vertical redistribution of the chlorophyll field, to a steadily moving storm. The model is forced by a prescribed wind and pressure field. The numerical experiments included a control run to analyze the horizontal and vertical structure of the chlorophyll field, and several sensitivity runs to investigate the response to changes in the storm parameters (translation speed, size and intensity) and the seasonal distribution of chlorophyll. The model results showed that after the passage of the storm, surface chlorophyll in the Labrador Sea is generally increased by vertical mixing. The largest increase occurs in autumn. In summer (control run), the surface chlorophyll concentration is 1 to $3 \mathrm{mg} \mathrm{m}^{-3}$ higher than the concentration before the storm in almost all the areas under the influence of the storm. In the shelf regions, however, the increase is very small. The changes in surface chlorophyll concentration are shown to be primarily controlled by the mixed-layer depth and the initial chlorophyll distribution. Nitrate brought from the deep reservoir to the mixed layer by entrainment was estimated from the model. For a typical storm in summer, $3.35 \times 10^{3} \mathrm{~mol}$ of new nitrate is added to the mixed layer for each $\mathrm{km}$ of storm track. Primary production rates following the introduction of new nitrate will contribute to further change in surface chlorophyll, but on a longer time scale.
\end{abstract}

KEY WORDS: Moving storm · Chlorophyll · Vertical distribution · 3-D model

\section{INTRODUCTION}

The seasonal cycle of stratification is one of the strongest of the physical phenomena that shape the dynamics of phytoplankton in the ocean. At any given time, the depth of the mixed layer is determined by the balance of 2 opposing trends: the stratifying tendency of solar heating and precipitation; and the tendency of wind mixing and surface cooling to erode stratification. The relative strengths of these 2 trends vary throughout the year. In general, the effect of wind is sustained and strong during winter, whereas the effect of the sun is sustained and strongest during summer. That the 2 trends are out of phase with each other accounts for the annual cycle of stratification, and stratification increases as summer succeeds spring, decreasing as autumn gives way to winter.
The principal biological effect of this cycle is that when the water column is stratified, the surface mixed layer (the layer in which illumination is optimal for photosynthesis) is isolated from the layer below (where the nutrient reservoirs are found). Once photosynthesis has exhausted the nitrate at the surface, re-supply through transport from below, against the density gradient, is difficult (Lewis et al. 1986). At this stage, photosynthesis may continue in the surface mixed layer, but using only reduced (recycled) nitrogen as a substrate. In general this may be sufficient to meet the metabolic demands of the pelagic community, but not to provide surplus production that could be used to increase system biomass; for example, biomass of exploitable fish stocks (Platt et al. 1992).

Of course, nutrients can be transported against the density gradient provided enough external energy is 
supplied. This can happen, for example, when a storm of sufficient strength passes over the area concerned (Platt et al. 2003). The vertical mixing induced by the storm increases the depth of the surface mixed layer and in the process entrains nitrate from the deep reservoir. The nitrate so entrained is referred to as new nitrogen, to indicate that its source is external to the layer where photosynthesis occurs. New nitrate can be used to increase biomass at any trophic level in the pelagic layer, and the biomass so produced may be removed (for example by fishing) without destroying the integrity of the pelagic ecosystem (Platt et al. 1992).

Using remotely sensed data, several authors have demonstrated local biomass changes following the passage of storms (Babin et al. 2004, Davis \& Yan 2004, Fuentes-Yaco et al. 2005, Platt et al. 2005, Son et al. 2006). Storms are, therefore, of fundamental importance to the dynamics of the ocean ecosystem, and we should try to understand in detail the way in which they exert their influence, and the limitations of their effect. Remotely-sensed data can give the distribution of biomass at the surface but no information about the change of vertical distribution and mixed-layer depth. Here, we apply a circulation model of the Labrador Sea to examine changes in the vertical distribution of phytoplankton biomass (indexed as the concentration of chlorophyll) to an intense storm moving through the area, and discuss the implications for nitrate distribution. The biological processes involving nitrate are not addressed. We seek to identify the physical mechanisms having the greatest control on the distribution of chlorophyll and nitrate, and to understand the dependence of the responses on properties of the storm, such as its size, intensity and translation speed. We discuss the spatial structure of the chlorophyll field following the storm and the extent to which the response might change with season.

\section{MODEL EQUATIONS AND MODEL SETUP}

Ocean model. To simulate the short-term change of the chlorophyll distribution under perturbation by the storm, we use a 3-D advection-diffusion equation embedded in a 3-D ocean circulation model. The ocean model is the Princeton Ocean Model (POM) implemented for the Labrador Sea. The model contains an embedded second-order turbulence closure sub-model, which takes into account the effects of both wind mixing and wave dissipation (Mellor \& Blumberg 2004). The vertical eddy viscosity is parameterized by a mixing length, the turbulence kinetic energy, and a stability factor which depends on the vertical shear and buoyancy. The setup of the model has been de-

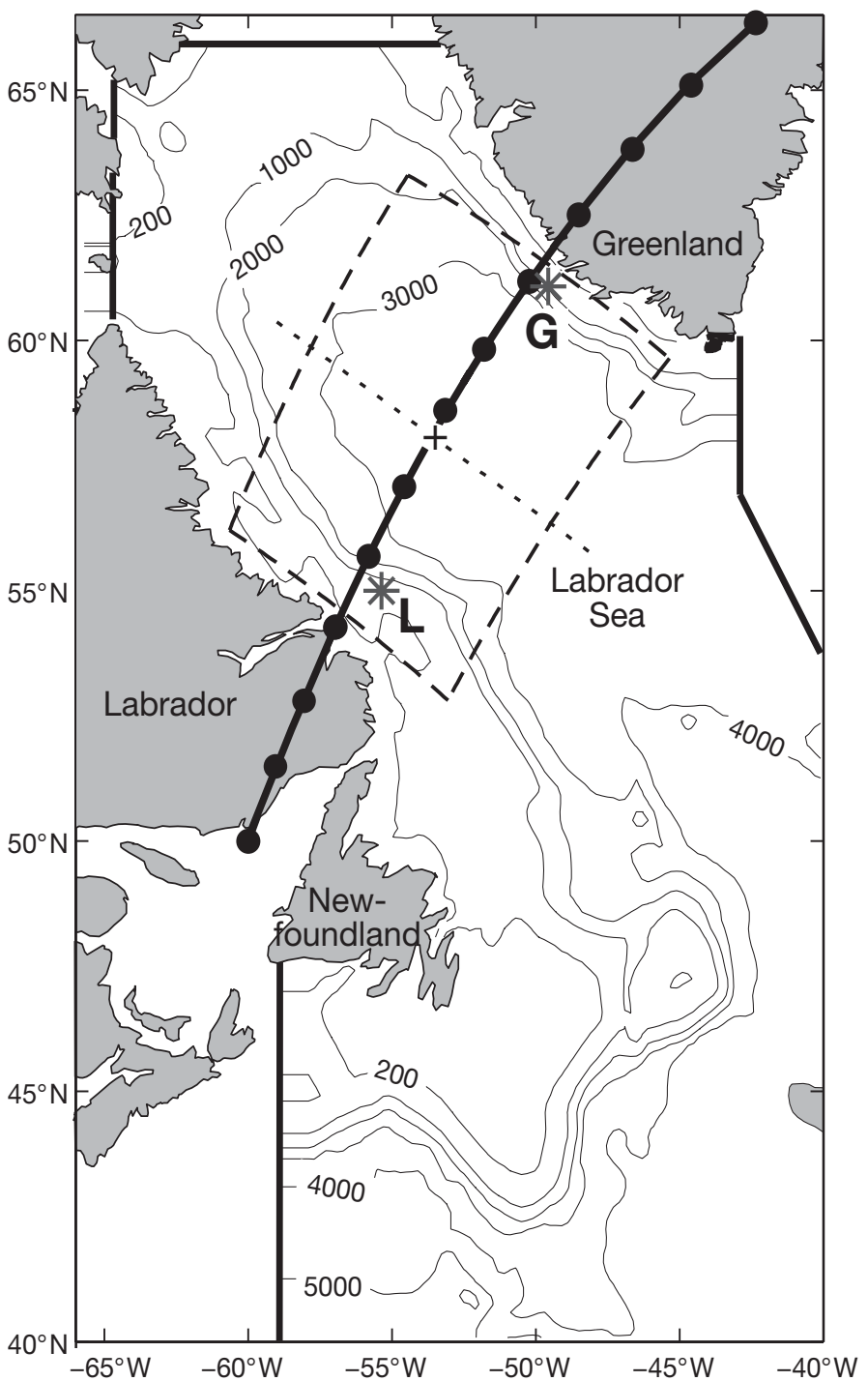

Fig. 1. Model domain and storm track. The model boundaries are indicated by the thick lines. The bold solid line with solid dots indicates the storm track. The solid dots denote the storm position at the time step of $6 \mathrm{~h}$. +: marks the site referred to in Figs. $4 \& 5$. The box outlined by dashed lines defines the area used in Figs. 6 \& 9. Sites L and G (*) are used in Fig. 8. The dotted line is the cross-track section in Figs. $7 \& 10-13$

scribed in detail by Yao et al. (2000) and Wu et al. (unpubl.). The model domain is from $40^{\circ} \mathrm{N}$ to $66^{\circ} \mathrm{N}$ and from the Canadian east coast to $40^{\circ} \mathrm{W}$, with a horizontal resolution of approximately $20 \mathrm{~km} \times 20 \mathrm{~km}$ (Fig. 1). The vertical coordinate system is the generalized coordinate system which permits a z-level representation of the upper ocean everywhere in the model domain independent of water depth (Mellor et al. 2002). There are 30 vertical levels consisting of ten $2 \mathrm{~m}$ levels in the upper water column and 20 sigma levels (fixed fractions of the water depth) below. 
The conservation equation for the chlorophyll concentration can be written as (Fennel \& Neumann 2004):

$$
\frac{\partial C}{\partial t}+\mathbf{u} \times \nabla C+w \frac{\partial C}{\partial z}=\frac{\partial}{\partial z}\left(K_{\mathrm{H}} \frac{\partial C}{\partial z}\right)+F_{\mathrm{C}}+S
$$

where $C$ is the chlorophyll concentration in $\mathrm{mg} \mathrm{m}^{-3}$; $t$ is time; $\mathbf{u}$ is the velocity vector; $z$ is the vertical coordinate (positive downward), $w$ is the vertical velocity; $K_{\mathrm{H}}$ is the vertical diffusion coefficient; $F_{\mathrm{C}}$ is the horizontal diffusion term; and $S$ is the source/sink term which is the sum of biomass production and loss. We did not study the biological processes and hence set $S$ to zero. The method for solving Eq. (1) is similar to the method for solving the equation of temperature or salinity. Zero flux conditions are employed at the surface and bottom boundaries, and radiation conditions are used at lateral boundaries. In the present study, our focus is on physical processes with time scales of several days. The contribution of the growth and loss terms to the change of chlorophyll after the storms will be discussed elsewhere.

Storm model. We used a controllable wind and pressure field to simulate the effect of a moving storm. This approach has been taken by a number of investigators (O'Brien \& Reid 1967, Chang \& Anthes 1978, Price 1983, Tang et al. 1998). Following O'Brien \& Reid (1967) and Tang et al. (1998), the horizontal distribution of air pressure changes exponentially from the center to the periphery of the storm:

$$
p(r)=p_{\mathrm{c}}+\left(p_{\mathrm{n}}-p_{\mathrm{c}}\right) \times \mathrm{e}^{(-R / r)}
$$

where $p(r)$ is the air pressure at distance $r$ to the storm center. The quantities $p_{\mathrm{c}}$ and $p_{\mathrm{n}}$ are the pressures at the center and at the outer periphery, respectively, and $R$ is the radius of the storm. Using the gradient wind equations, we have the wind speed:

$$
V=\left[\frac{R}{\rho_{\mathrm{a}} r}\left(p_{\mathrm{n}}-p_{\mathrm{c}}\right) \mathrm{e}^{(-R / r)}+\frac{r^{2} f^{2}}{4}\right]^{1 / 2}-\frac{r f}{2}
$$

where $\rho_{\mathrm{a}}$ is the air density (assumed constant at $1.15 \mathrm{~kg} \mathrm{~m}^{-3}$ ) and $f$ is the Coriolis parameter. The radial and tangential velocities of surface wind, $V_{\mathrm{r}}$ and $V_{\theta}$, respectively, can be calculated from:

$$
\begin{aligned}
& V_{\mathrm{r}}=-0.7 V \beta \sin \alpha \\
& V_{\theta}=0.7 V \beta \cos \alpha
\end{aligned}
$$

where $\alpha$ is the inflow angle (the angle between the wind vector and the tangent to the local isobar), here set to $10^{\circ}$, and $\beta$ is an empirical function of $r$ :

$$
\beta=\left(1+\frac{\mathrm{d}^{2}}{r^{2}}\right)^{-1}
$$

where $\mathrm{d}(=5.088 \mathrm{~km})$ is an empirical distance scale originally given in miles in O'Brien \& Reid (1967). These equations represent the wind field for an axially symmetric storm.

A typical storm over the Labrador Sea moves from southern Labrador or northern Newfoundland towards Greenland. As it moves across the ocean, its intensity decreases. Some storms weaken and dissipate before reaching the coast of Greenland and some veer to the southeast. Here, the storm track used for all experiments was a straight line from southern Labrador to southwestern Greenland (see Fig. 1). The typical parameter values for the reference run (Table 1) are based on data from the Canadian Meteorological Centre and the European Centre for Medium-range Weather Forecasts (Tang et al. 1998): $R=100 \mathrm{~km}, p_{\mathrm{n}}=101.3 \mathrm{kPa}, p_{\mathrm{c}}=94.0 \mathrm{kP}$ a the translation speed, $U_{\mathrm{H}}=8.0 \mathrm{~m} \mathrm{~s}^{-1}$. Wind speeds across the storm for 3 difference values of central pressure are shown in Fig. 2. The cross-storm variation is characterized by a sharp drop in wind speed toward the storm center and a gradual decrease from the maximum outward.

Model initialization. The initial conditions for the physical components of the model, such as currents, temperature and salinity, were obtained from the results of a diagnostic-prognostic spin-up. The 3-D ocean temperature and salinity fields used in the spin-up are the seasonal climatology data obtained from an objective analysis of bottle and CTD records (dating back to 1910) archived at the Bedford Institute of Oceanography (Tang \& Wang 1996). The vertical distribution of the initial chlorophyll concentration before the storm was specified with the para-

Table 1. Parameters used in the numerical experiments. ${ }^{*}$ The parameter has the same value as the value in Run 1 (= Reference Run)

\begin{tabular}{|lcccc|}
\hline \multirow{2}{*}{ Run } & \multirow{2}{*}{$\begin{array}{c}\text { Chlorophyll } \\
\text { profile } \\
\text { and ocean }\end{array}$} & $\begin{array}{c}\text { Translation } \\
\text { speed } \\
\left(\mathrm{m} \mathrm{s}^{-1}\right)\end{array}$ & $\begin{array}{c}\text { Radius } \\
(\mathrm{km})\end{array}$ & $\begin{array}{c}\text { Air pressure } \\
\text { difference } \\
(\mathrm{kPa})\end{array}$ \\
\hline 1 (Reference) & Summer & 8 & 100 & 7.3 \\
2 & $*$ & 4 & $*$ & $*$ \\
3 & $*$ & 12 & $*$ & $*$ \\
4 & $*$ & $*$ & 60 & $*$ \\
5 & $*$ & $*$ & 140 & $*$ \\
6 & $*$ & $*$ & $*$ & 3.3 \\
7 & $*$ & $*$ & $*$ & $*$ \\
8 & Autumn & $*$ & $*$ & $*$ \\
9 & Winter & $*$ & $*$ & $*$ \\
10 & Spring & $*$ & & $*$ \\
\hline
\end{tabular}




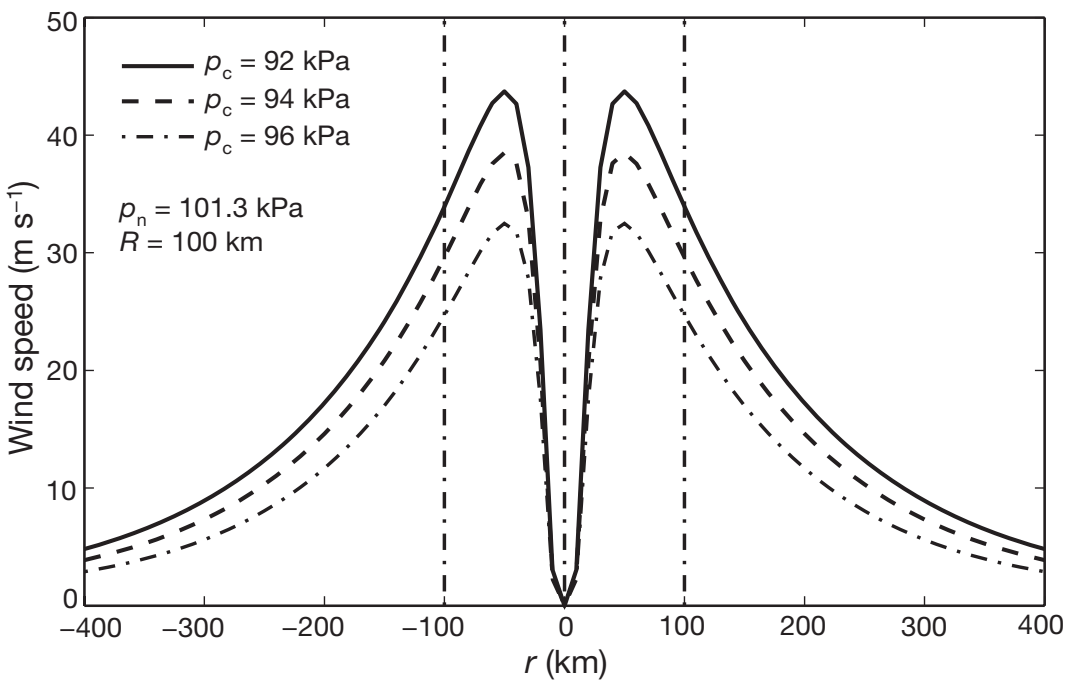

Fig. 2. Wind speed profiles $\left(V_{\mathrm{r}}^{2}+V_{\theta}^{2}\right)^{1 / 2}$ for different central pressures. $r$ : distance to centre of storm. See Eqs. (2)-(6)

meterization of Platt et al. (1991). The parameters were extracted from 873 chlorophyll profiles observed in the North Atlantic between 1960 and 1990, and sorted by season and region.

The vertical distribution of chlorophyll, $C_{0}(z)$, is expressed as a shifted Gaussian distribution:

$$
C_{0}(z) \equiv C(z, t=0)=B+\frac{h}{\sigma \sqrt{2 \pi}} \exp \left(-\frac{\left(z-z_{\mathrm{m}}\right)^{2}}{2 \sigma^{2}}\right)
$$

where $B$ is a background value, $h$ is the total biomass at the peak, $\sigma$ is the width of the chlorophyll peak, and $z_{\mathrm{m}}$ is the depth of the chlorophyll maximum. The seasonal and regional characteristics of $C_{0}(z)$ are characterized by these 4 parameters. To reduce the degrees of freedom from 4 to 3 , a dimensionless parameter $\rho$, the ratio of the peak biomass to the background value, can be defined as:

$$
\rho=h /\left[B \sigma(2 \pi)^{1 / 2}\right]
$$

The background value, $B$, can be determined if the surface concentration $C_{o}(0)$ is known. We assume that the surface chlorophyll is horizontally homogeneous in

Table 2. Surface concentration $B(0)$ and parameters of $B(z)$ in Labrador Sea region for different seasons. (The vertical profile in winter is uniform)

\begin{tabular}{|lcccc|}
\hline Season & $\begin{array}{c}B(0) \\
\left(\mathrm{mg} \mathrm{chl} \mathrm{m}^{-3}\right)\end{array}$ & $\rho$ & $\begin{array}{c}z_{\mathrm{m}} \\
(\mathrm{m})\end{array}$ & $\begin{array}{c}\sigma \\
(\mathrm{m})\end{array}$ \\
\hline Winter & 0.2 & & & \\
Spring & 1.5 & 34 & 15 & 12 \\
Summer & 1.0 & 6.95 & 36 & 10 \\
Autumn & 0.5 & 29.1 & 23 & 4 \\
\hline
\end{tabular}

the entire model domain. The values for different seasons, which are based on ocean color data from satellites, are given in Table 2. According to the classification of Platt et al. (1991), there are 6 regions in our model domain. Each region in each season has its own set of parameters. The parameter values for the Labrador Sea Region (latitude ranges from 51 to $70^{\circ} \mathrm{N}$ and depth is $>2000 \mathrm{~m}$ ) in different seasons are listed in Table 2. Fig. 3 shows $C_{0}(z)$ computed from Eq. (7) and parameters in Table 2.

The response of the chlorophyll field to a moving storm was investigated using the results of a series of numerical experiments (Table 1). The first (Run 1) is the reference run with typical storm parameters and the chlorophyll distribution for summer. In a group of 6 experiments (Runs 2 to 7), we used different translation speeds, air pressure differences, $\Delta p\left(=p_{\mathrm{n}}-p_{\mathrm{c}}\right)$, and radii. In another group of experiments (Runs 8-10), we kept the storm parameters unchanged and specified the initial chlorophyll distribution for the other 3 seasons. In each experiment, the model was run for $4 \mathrm{~d}$. We note that
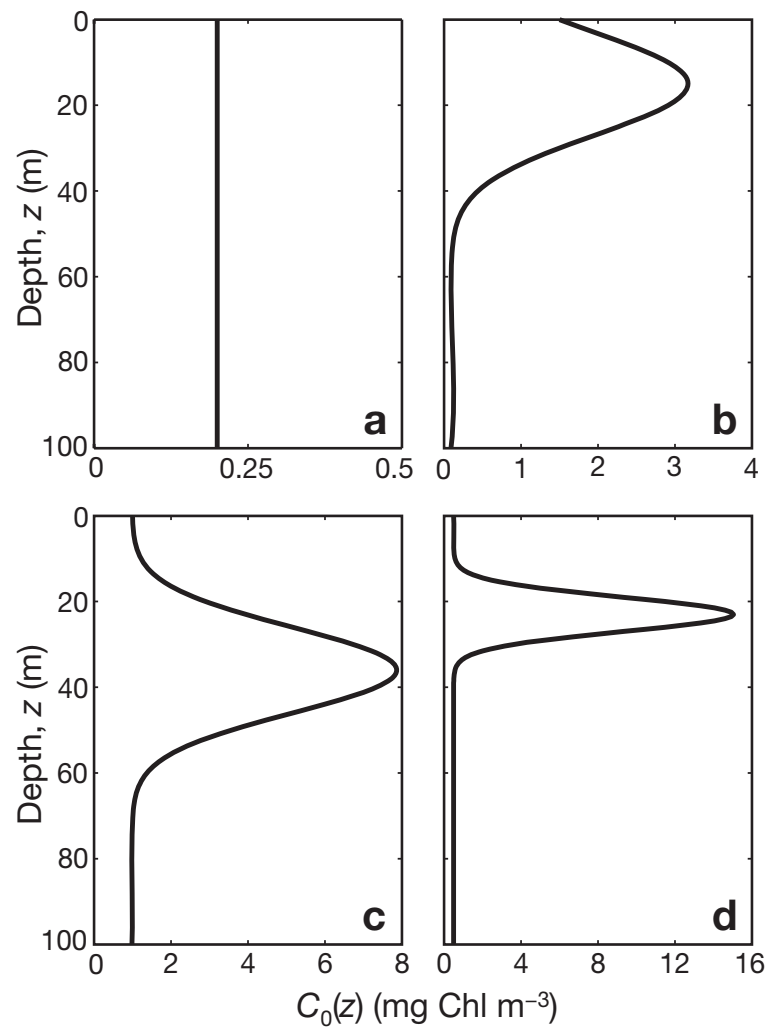

Fig. 3. Profiles of the vertical distribution $(z)$ of chlorophyll $C_{0}(z)$. (a) Winter, (b) spring, (c) summer, (d) autumn. Note the differences in the scales of $C_{0}(z)$. The maxima of spring, summer and autumn are $3.17,7.86$ and $15.0 \mathrm{mg} \mathrm{m}^{-3}$, respectively 

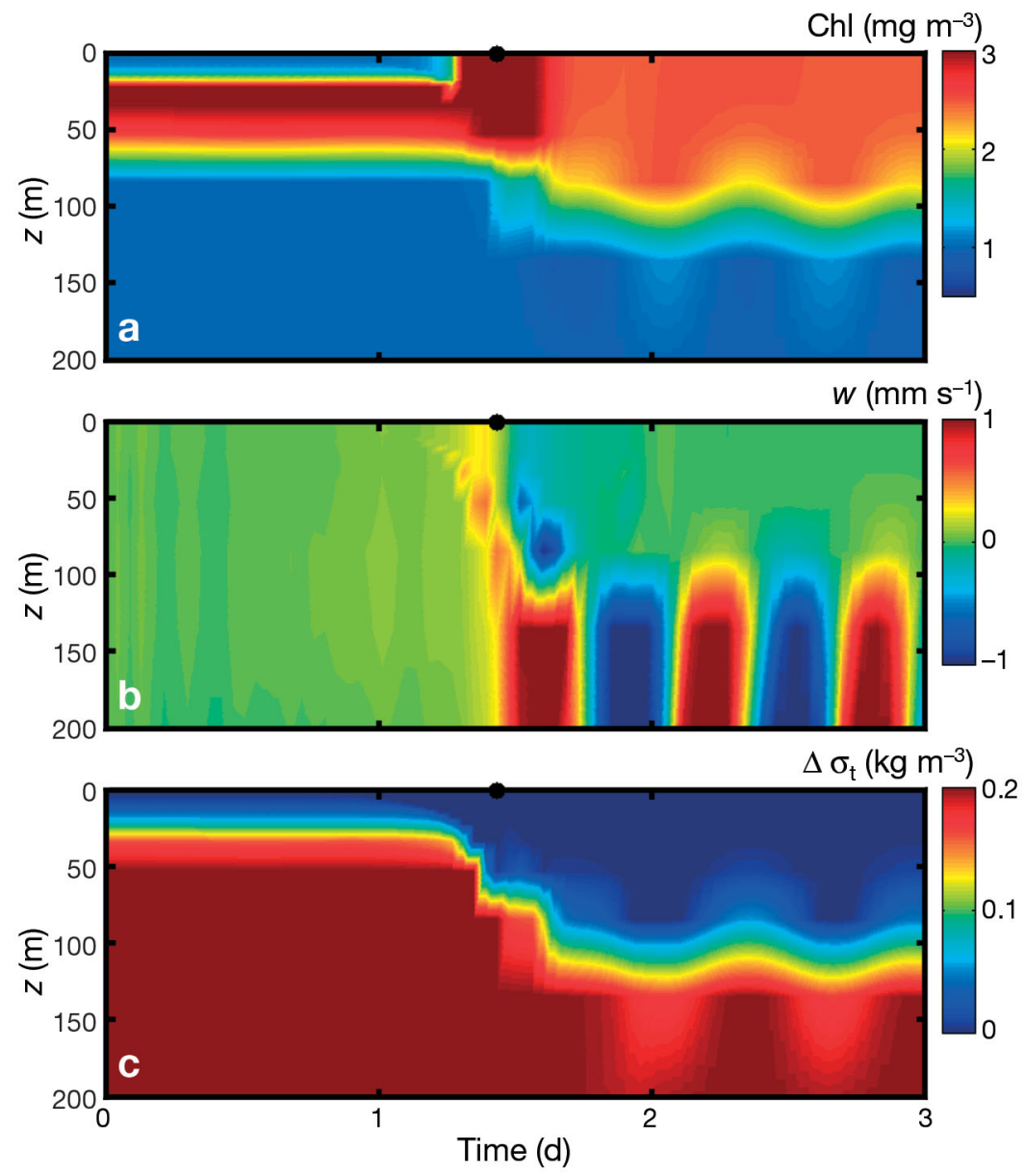

Fig. 4. Change in vertical distribution $(z)$ of: (a) chlorophyll; (b) vertical velocity $(w)$ and (c) density $\left(\Delta \sigma_{t}\right)$ relative to the surface value at the location denoted by the symbol + in Fig. 1. The solid dot at the top of each panel indicates the time at which the storm passes this location

\section{Vertical changes}

The response of the chlorophyll field to the storm may be divided into 2 stages. The first is the transient stage, which is relatively short, lasting for several hours after the passage of the storm. The second is the wake stage during which the current field is dominated by the inertial oscillation. When the storm passes over a given location, the initial Gaussian distribution is destroyed and the chlorophyll is redistributed uniformly within the upper layer (Fig. 4a) by vertical water motion (Fig. 4b). Fig. 4c displays density at depth relative to the surface value. The surface mixed layer depth (MLD) can be estimated using a specific criterion of density difference. For a density difference of $0.1 \mathrm{~kg}$ $\mathrm{m}^{-3}$, the MLD deepens from $15 \mathrm{~m}$ before the storm to $60 \mathrm{~m}$ after the storm. The MLD is not sensitive to the value of the density difference, because the density gradients at the base of the mixed layer are large. After the passage of the storm, the chlorophyll concentration remains uniform within the surface mixed layer, and the MLD oscillates at the inertial frequency. The surface chlorophyll concentration increases slightly during upwelling and decreases slightly during downwelling as a result of the vertical motion of the water (Fig. 4b).

Fig. 5 shows the chlorophyll and temperature profiles before and after the storm.

the time for the storm to cross the Labrador Sea is only $34 \mathrm{~h}$ in the reference run (see Fig. 1). Since the heat budget of the surface mixed layer following the perturbation is dominated by storm-induced entrainment and mixing, we neglected heat exchange between the atmosphere and the ocean (O'Brien \& Reid 1967, Chang \& Anthes 1978). The surface flux of fresh water was also set to zero.

\section{RESULTS}

\section{Spatial and temporal changes in summer (Run 1)}

We define the change of chlorophyll in the surface mixed layer, $\Delta c h l$, in response to the storm as:

$$
\Delta c h l=C_{\mathrm{a}}-C_{\mathrm{b}}
$$

where $C_{\mathrm{b}}$ and $C_{\mathrm{a}}$ are the chlorophyll concentrations before and after the storm, respectively.
The surface chlorophyll increases from 1.0 to $2.8 \mathrm{mg}$ $\mathrm{m}^{-3}$. The peak centered at $38 \mathrm{~m}$ is smoothed. In con-
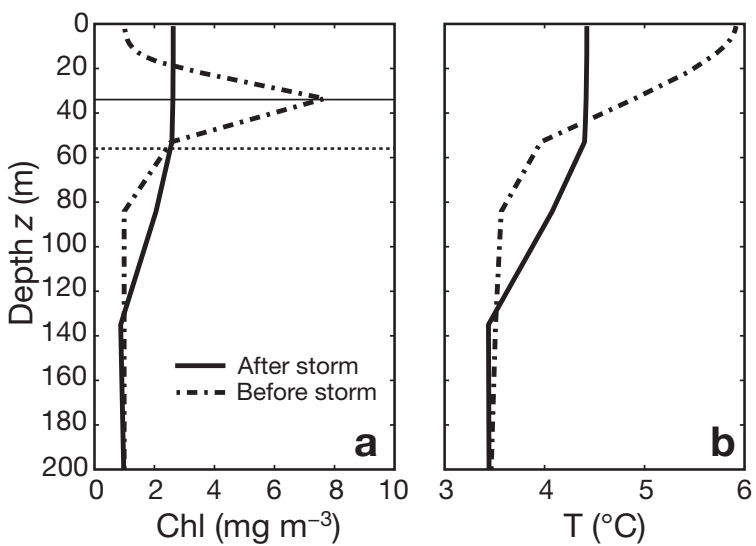

Fig. 5. Vertical profiles (z) of (a) chlorophyll and (b) temperature before and $5 \mathrm{~h}$ after the storm in summer. The horizontal solid and dash-dotted lines in (a) denote $z_{\mathrm{m}}$ and $z_{\mathrm{m}}+2 \sigma$ respectively 


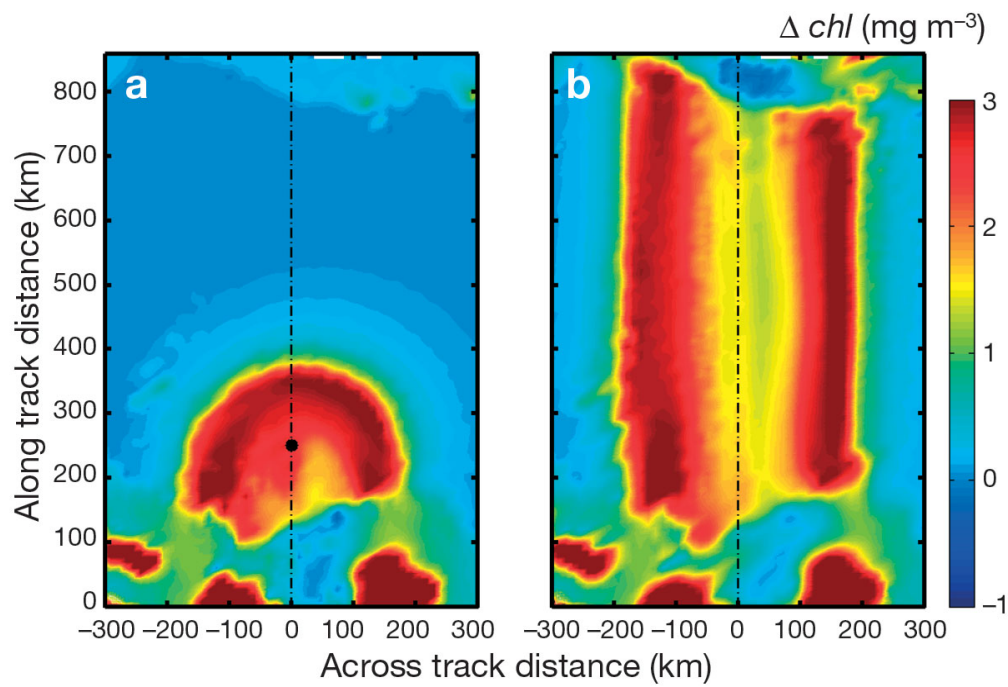

Fig. 6. Surface $\Delta c h l$ during and after passage of the storm at (a) $30 \mathrm{~h}$ and (b) $58 \mathrm{~h}$. The area is indicated by the dot-dashed rectangular box in Fig. 1. The solid dot in (a) indicates the location of the storm center at $30 \mathrm{~h}$

same location as the MLD maximum. It is apparent that $\triangle S S T$ is closely related to the MLD. The slight difference in $\Delta c h l$ on the 2 sides near the centre of the storm is associated with the asymmetry in $D$. The peaks of $\Delta c h l$ on the 2 sides occur at $160 \mathrm{~km}$ from the track. The mixed layers at these locations have similar mixed layer depths (45 m).

The distribution of surface chlorophyll is dependent on the initial distribution and the intensity of mixing. For a given initial chlorophyll distribution (Fig. 5), the change of surface chlorophyll is controlled by $D$, the depth of maximum chlorophyll concentration, $z_{\mathrm{m}}$ (both $D$ and $z_{\mathrm{m}}$ are positive) and the width of the chlorophyll peak, $\sigma$ (Fig. 7b). For $D<z_{\mathrm{m}}, \Delta c h l$ increases with increasing MLD. For $D>z_{\mathrm{m}}+2 \sigma$, on the other hand, it decreases with increasing MLD. The response $\Delta c h l$ can be negative if surface chlorophyll concentration is high and

trast, the sea surface temperature decreases by $1.6^{\circ} \mathrm{C}$ as a result of mixing of the warm surface water and the cold subsurface water.

\section{Horizontal changes}

We focus the analysis of the model results on a rectangular region around the storm track measuring $600 \mathrm{~km}$ in the across-storm track direction and more than $850 \mathrm{~km}$ in the along-storm track direction (see the box in Fig. 1). Fig. 6a shows $\Delta c h l$ at $t=30 \mathrm{~h}$ when the storm is $12 \mathrm{~h}$ from the Labrador coast (see Fig. 1), and Fig. $6 \mathrm{~b}$ shows $\Delta c h l$ when $t=58 \mathrm{~h}$, when the storm has passed the study area. The most prominent feature of Fig. 6a is an area of high concentration in the shape of an inverted ' $U$ '. The apex of the inverted ' $U$ ' moves with the storm. The storm eye lags the head by about $120 \mathrm{~km}$. After passage of the storm (Fig. 6b), the area of high concentration forms 2 parallel bands on both sides of the storm track, and between them is an area of moderate concentration.

Fig. 7 shows $\Delta c h l, D$ (the depth of the base of the mixed layer) and the cooling of the sea surface $(\Delta S S T)$ along a section perpendicular to the storm track in the middle of the Labrador Sea (see Fig. 1 for location). The 2 maxima are slightly shifted to the right. $\Delta c h l$ values on the 2 sides of the track have similar magnitudes (the right side is larger). The $\Delta S S T$ plot (Fig. $7 \mathrm{c}$ ) suggests more intense cooling on the right side of the storm. The asymmetry is caused by the higher wind speeds on the right side, owing to the movement of the storm. The maximum cooling, $-1.7^{\circ} \mathrm{C}$, occurs at about $55 \mathrm{~km}$ to the right of the storm track, which is at the the final MLD is sufficiently deep. The maximum $\Delta c h l$ occurs when $D$ falls between $z_{\mathrm{m}}$ and $z_{\mathrm{m}}+2 \sigma$, i.e. $36 \mathrm{~m}$ and $56 \mathrm{~m}$, respectively, for the initial distribution in Fig. 5. Such a relationship among $\Delta c h l, D, z_{\mathrm{m}}$ and $\sigma$ is easy to understand. A shallow mixed layer can not reach the biomass below $z_{\mathrm{m}}$, whereas a deep mixed layer can dilute the biomass at its maximum.
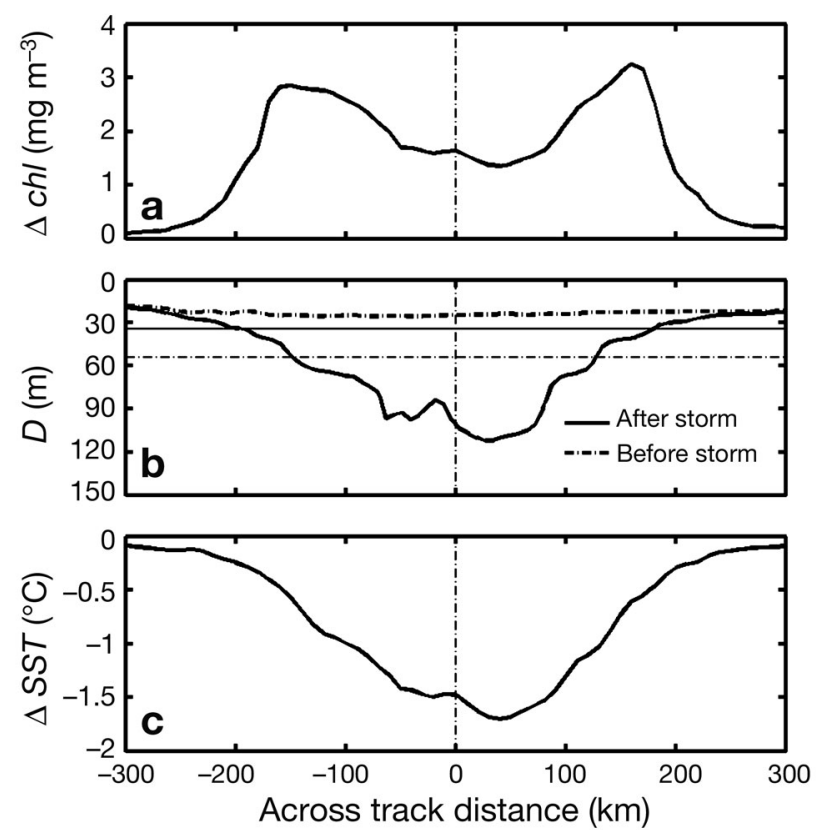

Fig. 7. (a) Change in surface chlorophyll $(\Delta c h l)$, (b) surface mixed layer depth (MLD) ( $D$ ) before (heavy dash-dotted line) and $5 \mathrm{~h}$ after (heavy solid line) the storm; and (c) $\triangle S S T$, in the cross-track section indicated by the dotted line in Fig. 1. The thin horizontal solid and dash-dotted lines in (b) denote $z_{\mathrm{m}}$ and $z_{\mathrm{m}}+2 \sigma$ respectively 
In contrast to the case for the open ocean, where the surface concentration increases by vertical mixing, the chlorophyll distribution on the Labrador shelf and west Greenland shelf has large areas of low $\Delta c h l$ (Fig. 6). The undulating structure along the shelves seen in Fig. 6 can be associated with the topographic waves excited by the storm. During and after the passage of the storm, a complex horizontal velocity field is developed over the shelf (Tang et al. 1998). The velocity field is composed of permanent currents, direct windforced currents, topographic waves, low-frequency currents and trapped inertio-gravity waves. The divergence and convergence of the currents over the topography can give rise to vertical motion. We propose that upwelling resulting from such vertical motion can contribute to the reduced $\Delta c h l$ on the shelf. Fig. 8 shows the change in chlorophyll concentration in the $z$ - $t$ plane at sites L (Fig. 8a) and G (Fig. 8b) on the shelf edge (see Fig. 1 for locations). The surface chlorophyll first increases during the storm, and then drops to the ambient value several hours after the storm. It is clear from Fig. 8 that the mechanism responsible for the variation of chlorophyll concentration is more than vertical mixing.

The large vertical velocities generated during and after the storm are shown in Fig. 4b. To determine whether they can lead to upwelling, we integrated the vertical velocity at $50 \mathrm{~m}$ from $1 \mathrm{~h}$ (the start of the storm) to $30 \mathrm{~h}$ and $58 \mathrm{~h}$, corresponding to the times of Figs. $6 \mathrm{a}$ and $6 \mathrm{~b}$, respectively. The resulting vertical displacement fields (Fig. 9) show that the vertical displacement is positive with a maximum value of $20 \mathrm{~m}$ in the areas of low chlorophyll concentration off the Labrador and Greenland coast (Fig. 6b). Positive vertical displacement indicates upwelling. In the shelf regions, lowchlorophyll water below the mixed layer is lifted to the mixed layer to replace the chlorophyll-rich water created by vertical mixing.

\section{Sensitivity to storm parameters (Runs 2 to 7 )}

The physical response of the ocean to moving storms of dissimilar intensity, size and translation speed has been investigated in several previous numerical studies (Chang \& Anthes 1978, Price 1981, Tang et al. 1998). Our objective in this subsection is to examine how the chlorophyll field responds to the changes in translation speed, size and intensity of a storm.

\section{Translation speed}

Low $\left(U_{\mathrm{H}}=4 \mathrm{~m} \mathrm{~s}^{-1}\right)$ and a high $\left(U_{\mathrm{H}}=12 \mathrm{~m} \mathrm{~s}^{-1}\right)$ translation speeds were used in Runs 2 and 3, respectively. As in the control experiment (Fig. 6), the high response region from these runs has the shape of an inverted ' $U$ ' and 2 parallel lines (not shown). The MLD is highly sensitive to the translation speed (Fig. 10). The maximum MLD from the low-speed run is $180 \mathrm{~m}$, whereas that from the high-speed run is only $100 \mathrm{~m}$. The large difference is easy to understand. A reduction in the

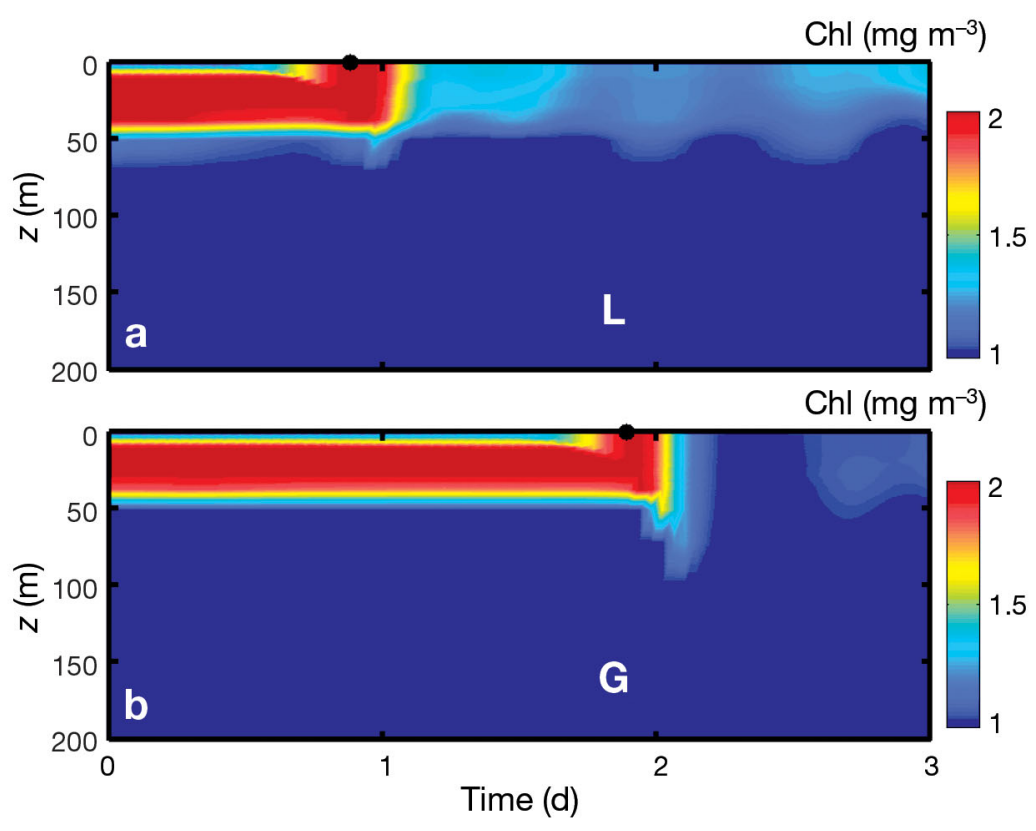

Fig. 8. Vertical distribution (z) of chlorophyll with time at (a) Labrador coast, L; and (b) Greenland coast, G (see Fig. 1 for locations)
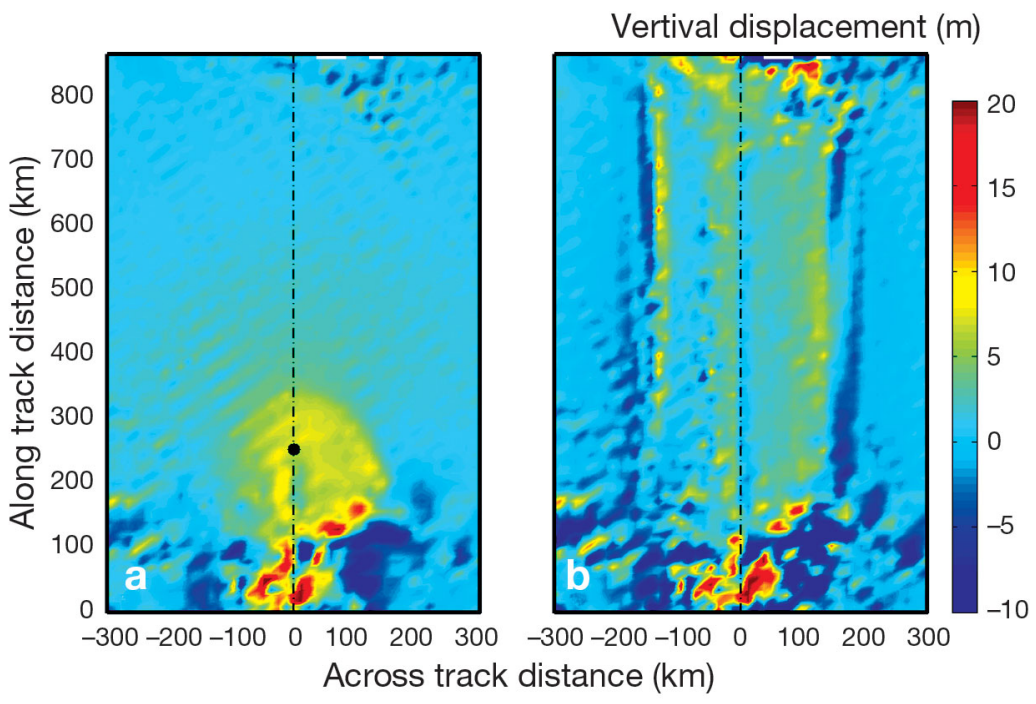

Fig. 9. Vertical displacement indicating upwelling/downwelling during and after the passage of the storm at (a) $30 \mathrm{~h}$ and (b) $58 \mathrm{~h}$. The geographic area is indicated by the dot-dashed rectangular box in Fig. 1. The solid dot in (a) indicates the location of the storm center at $30 \mathrm{~h}$ 
translation speed means a longer time for wind mixing to operate on the ocean and hence more turbulence kinetic energy is generated in the ocean, resulting in a deeper mixed layer.

For the chlorophyll concentration, we divided the area affected by the storm into an inner region (between the 2 chlorophyll peaks) and the outer region

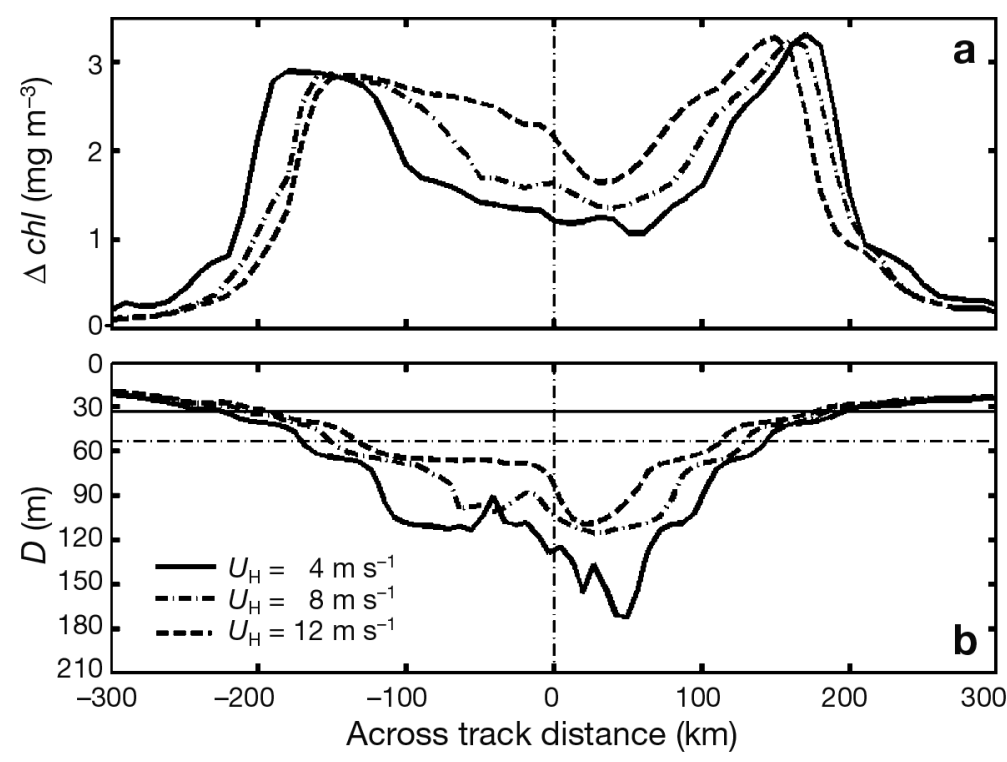

Fig. 10. (a) Change of surface chlorophyll ( $\Delta c h l$ ), (b) MLD (D), over the cross-track section indicated by the dotted line in Fig. 1, for 3 translation speeds $\left(U_{\mathrm{H}}\right)$. The thin horizontal solid and dash-dotted lines in (b) denote $z_{\mathrm{m}}$ and $z_{\mathrm{m}}+2 \sigma$ respectively
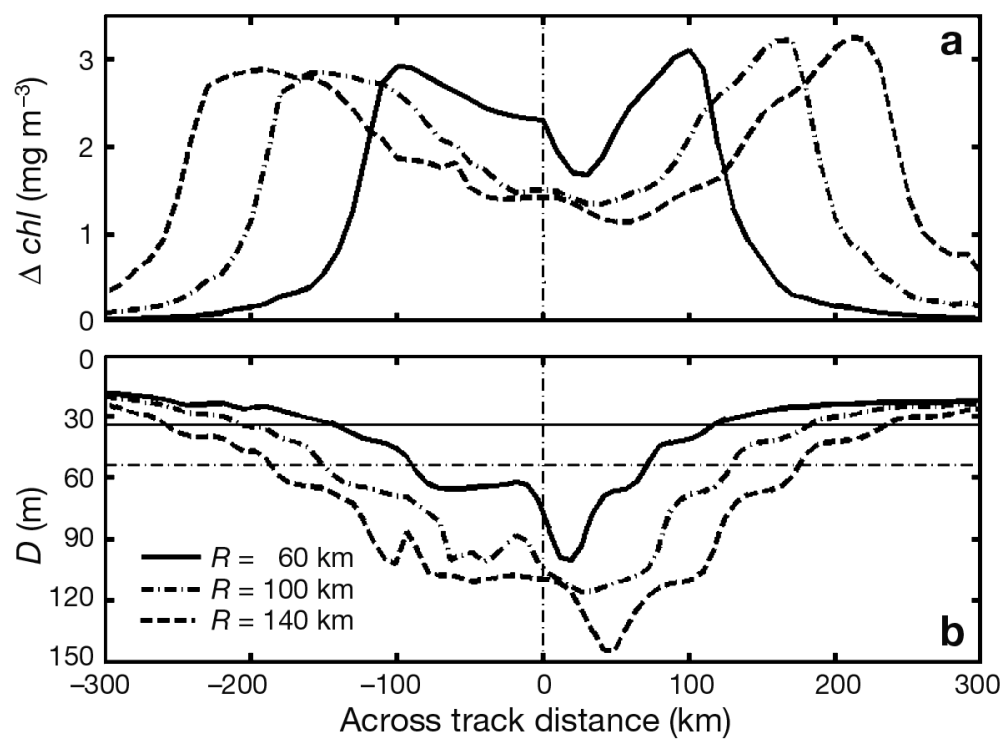

Fig. 11. (a) Change of surface chlorophyll $(\Delta c h l)$, (b) MLD base depth $(D)$, over the cross-track section indicated by the dotted line in Fig. 1, for different radii $(R)$ and $U_{\mathrm{H}}=8 \mathrm{~m} \mathrm{~s}^{-1}$. The thin horizontal solid and dashdotted lines in (b) denote $z_{\mathrm{m}}$ and $z_{\mathrm{m}}+2 \sigma$ respectively (outside the chlorophyll peaks). In the inner region, the surface chlorophyll increases with the translation speed. In the outer region, the relationship is reversed. The reason for the different behaviours is that in the inner region $D>z_{\mathrm{m}}+2 \sigma$ and $\Delta c h l$ is inversely proportional to the MLD, and in the outer region $D<z_{\mathrm{m}}$ and $\Delta c h l$ is proportional to the MLD. The peak values of $\Delta c h l$ on both sides of the storm track, however, are not sensitive to the translation speed. This is because the peak values are controlled mainly by $D$, which does not change much with the translation speed at the locations of the peaks.

\section{Storm size and intensity}

In Runs 4 and 5, radii $R$ of $60 \mathrm{~km}$ (small storm) and $140 \mathrm{~km}$ (large storm) were used. For the same $p_{\mathrm{n}}$ and $p_{\mathrm{c}}$, the large storm covers a greater area with high wind, although the maximum wind speed is lower than the maximum in the small storm. Fig. 11 shows the change of $\Delta c h l$ and MLD in the cross-track section for different storm sizes. The final MLD increases with the storm size. The response $\Delta c h l$ decreases in the inner region and increases in the outer region with the storm size. These changes are primarily a result of vertical mixing, which smoothes out the vertical distribution and thus changes the surface value of chlorophyll concentration. The affected area increases with the storm size as expected, but the maximum $\Delta c h l$ is not sensitive to $R$.

The air pressure difference $\Delta p=p_{\mathrm{n}}-p_{\mathrm{c}}$ is a measure of the intensity of the storm. It can be altered by keeping the ambient pressure $p_{\mathrm{n}}$ constant and changing the center pressure $p_{\mathrm{c}}$. The results for 3 different $\Delta p$ are shown in Fig. 12. With an increase of $\Delta p$ from $3.3 \mathrm{kPa}$ to $11.3 \mathrm{kPa}$, the maximum MLD increases from $50 \mathrm{~m}$ to 200 m. $\Delta c h l$ decreases and increases with $\Delta p$ in the inner and outer regions, respectively. The maximum $\Delta c h l$ is not sensitive to $\Delta p$.

\section{Chlorophyll response in different seasons (Runs 8 to 10)}

The response of the chlorophyll field to passage of a storm depends on the degree of stratification in the water column, which 
is a seasonally varying property. If the water column is already well mixed (for example winter condition in temperate latitudes), the passage of even a strong storm may have only a limited effect. In early spring, even with incipient stratification, the surface mixed layer may still be nutrient replete, so that entrainment of more nutrients by vertical mixing will have little effect on primary production. However, any newly produced biomass at the surface may be redistributed in the vertical plane, with an initial apparent reduction
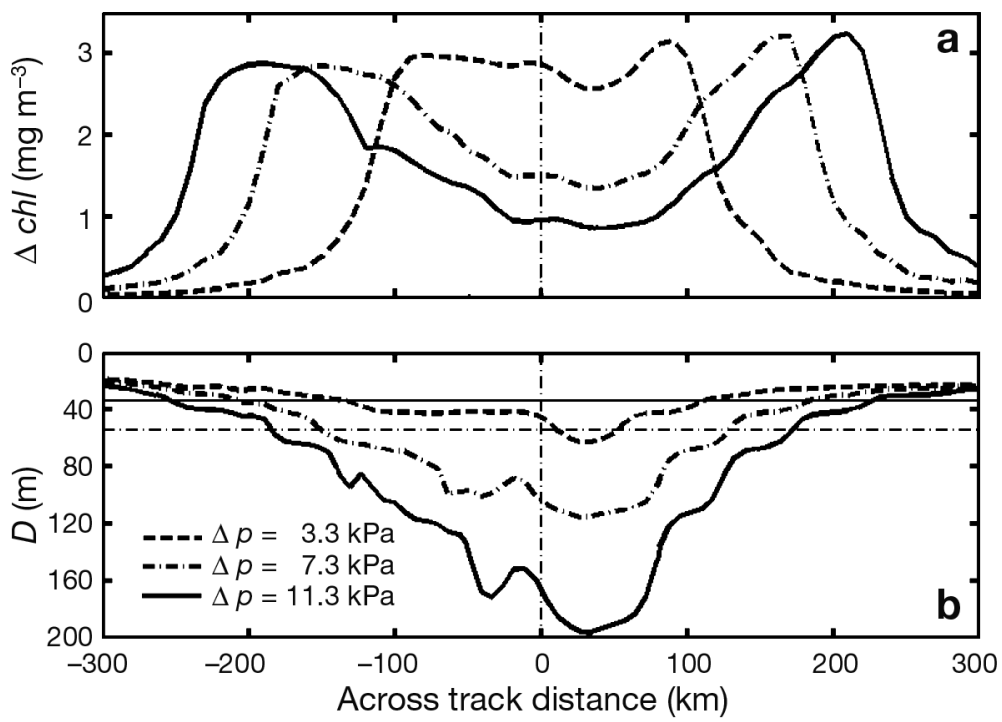

Fig. 12. (a) Change of surface chlorophyll $(\Delta c h l)$, (b) MLD (D), over the cross-track section indicated by the dotted line in Fig. 1, for different air pressure differences. The thin horizontal solid and dash-dotted lines in (b) denote $z_{\mathrm{m}}$ and $z_{\mathrm{m}}+2 \sigma$ respectively

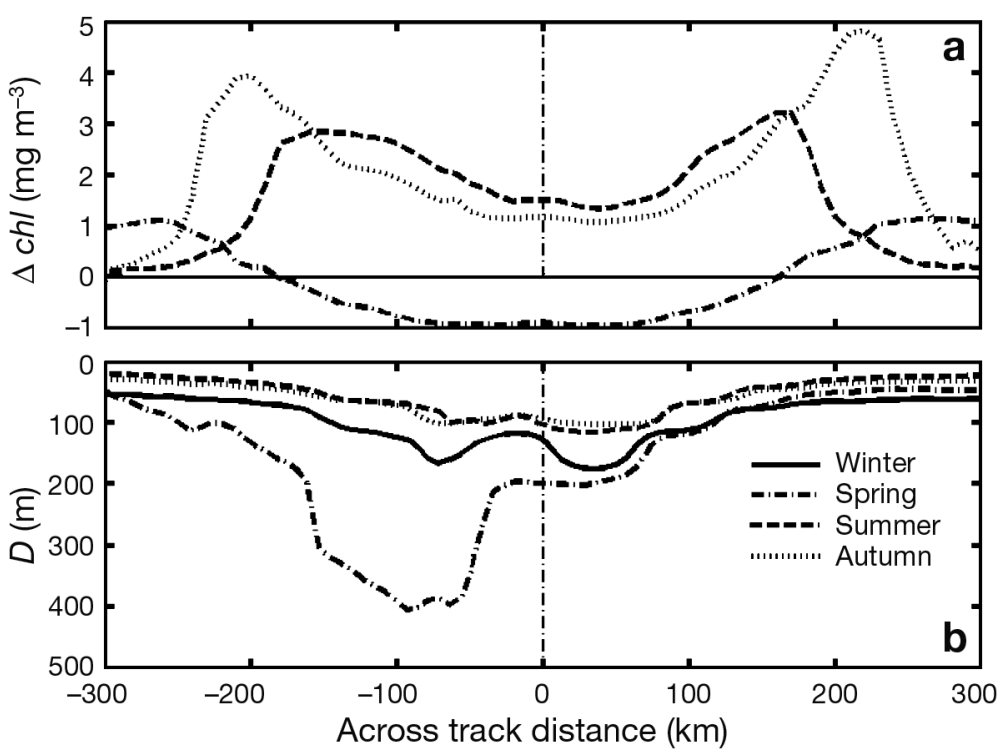

Fig. 13. (a) Change in surface chlorophyll $(\Delta c h l)$, (b) MLD, over the crosstrack section indicated by the dotted line in Fig. 1, for different seasons in chlorophyll. It is in the summer and autumn that we might expect the most pronounced effect. At this time, nutrients are usually exhausted at the surface, and any entrainment of nitrate into the surface mixed layer should provoke a rapid response in phytoplankton growth. The strength of the response will be greater the longer conditions have been stable (free of perturbation by wind). If several storms pass through an area in rapid succession, the response to the later storms will be attenuated because the earlier ones will have already mixed the water column, entraining nitrate. Hence, further disturbance has little further effect.

To investigate the response in different seasons, we ran the model (Runs 8 to 10) with the initial chlorophyll profiles given in Fig. 3 and Table 2. The storm has no effect on the surface chlorophyll in winter because initial chlorophyll distribution is uniform. The initial chlorophyll distribution for spring is characterized by a surface value much higher than values below $60 \mathrm{~m}$ (Fig. 3b). As a result, the surface chlorophyll in much of the inner region decreases after the storm, because of deep mixing. The different initial distributions in autumn and summer (Fig. 3) lead to different maximum values of $\Delta c h l$ and locations (Fig. 13a) although the mixed layer depths in the 2 seasons (Fig. 13b) are similar. The mixed layer deepens toward winter and reaches a maximum in spring. The asymmetry across the storm track shown in the spring MLD is caused by the change in ocean density from southern to northern Labrador Sea.

\section{Entrainment of nitrate}

As an application of the storm model, we estimated the nitrate entrained into the mixed layer by storm-induced vertical mixing using a simple 2-layer model for nitrate. The conceptual change of the nitrate distribution before and after the storm is shown in Fig. 14. If we know the initial surface and deep-water values, $N_{\mathrm{b}}$ and $N_{\mathrm{d}}$, and MLD after the storm, $D_{a}$, the nitrate brought from the deep reservoir to the initial mixed layer, $F$, by the storm is given by:

$$
F=D_{\mathrm{b}}\left(N_{\mathrm{a}}-N_{\mathrm{b}}\right)
$$

where $D_{\mathrm{b}}$ is the MLD before the storm and $N_{\mathrm{a}}$ is the nitrate concentration after the 


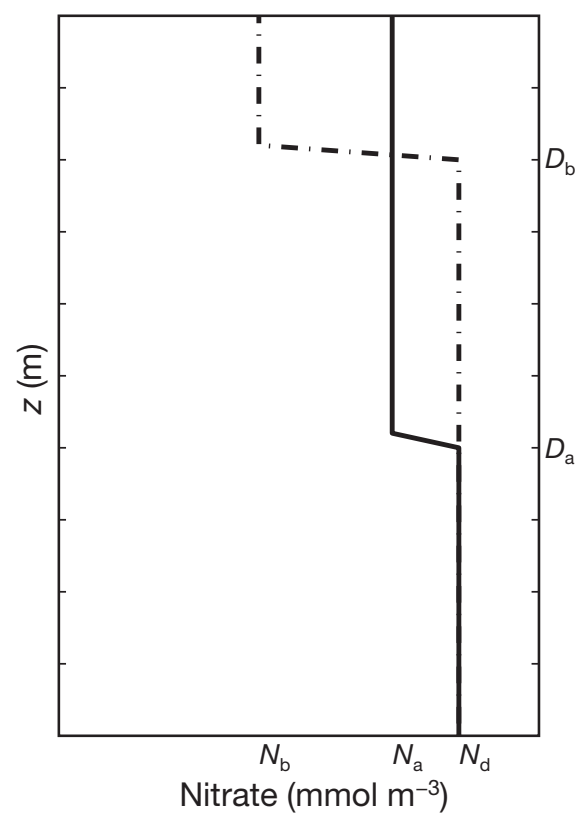

Fig. 14. Schematic diagram of vertical profiles $(z)$ of nitrate distribution before (dot-dashed line) and after (solid line) the storm. See Eqs. (10) to (12) for definitions of other terms
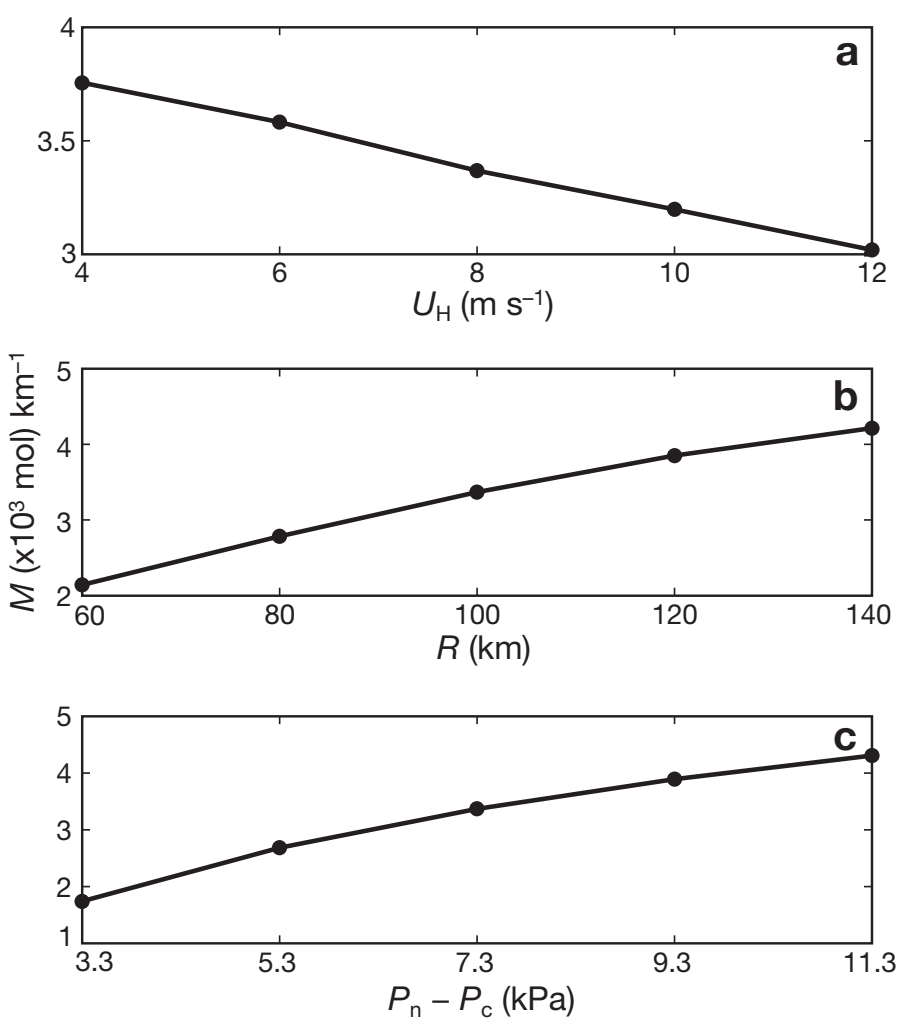

Fig. 15. Change of nitrate mass $M$ entrained to the mixed layer with: (a) storm speed $\left(U_{\mathrm{H}}\right)$; (b) size ( $R$ : radius) and (c) air pressure difference $P_{\mathrm{n}}-P_{\mathrm{c}}$ storm. By assuming the total nitrate in the water column is conserved before and after the storm, $N_{\mathrm{a}}$ can be computed given $D_{\mathrm{a}}$ :

$$
N_{\mathrm{a}}=\frac{D_{\mathrm{b}} \times N_{\mathrm{b}}+\left(D_{\mathrm{a}}-D_{\mathrm{b}}\right) \times N_{\mathrm{d}}}{D_{\mathrm{a}}}
$$

The amount of nitrate entrained from the lower layer to the mixed layer per unit distance of the storm track is given by:

$$
M=\int_{y} F \mathrm{~d} y
$$

where $y$ is in the cross-track direction and the integration is over the dotted line in Fig. 1. Given the values $N_{\mathrm{b}}=0.5 \mathrm{mmol} \mathrm{m}^{-3}$ and $N_{\mathrm{d}}=1.0 \mathrm{mmol} \mathrm{m}^{-3}$, and $D_{\mathrm{a}}$ from Runs 1 to 7 and additional runs, we obtain $M$ as a function of the translation speed, radius and depression (Fig. 15).

Fig. 15 shows that for a typical storm in summer (Run 1), $3.35 \times 10^{3} \mathrm{~mol}$ of nitrate for each $\mathrm{km}$ of the storm track is added to the mixed layer, and the surface value increases by $47 \%$. The quantity $M$ decreases with the translation speed and increases with the radius and depression. More nitrate will be brought to the surface by slower, larger and more intense storms. Although the total masses of chlorophyll and nitrate cannot be changed by the storm (leaving aside phytoplankton growth), new nitrate is entrained from the deep reservoir to the mixed layer by the storm, and can be used to increase biomass at any trophic level.

\section{DISCUSSION}

We have demonstrated that changes in surface chlorophyll through redistribution are highly sensitive to the final MLD. The effect of the MLD, is however nonlinear, i.e. a greater MLD may not always lead to a higher concentration. An interesting question that we now address is: for a given initial vertical distribution, does there exist an optimum final MLD that will produce the maximum increase in surface chlorophyll? We use a simple analytical model to answer this question.

In terms of surface chlorophyll $B_{\mathrm{s}}$, the chlorophyll distribution before the storm can be rewritten as:

where

$$
C(z)=C_{0} a\left(1+\rho \mathrm{e}^{\left(-\frac{\left(z-z_{\mathrm{m}}\right)^{2}}{2 \sigma^{2}}\right)}\right)
$$

$$
a=\frac{1}{1+\rho \mathrm{e}^{-z_{\mathrm{m}}^{2} /\left(2 \sigma^{2}\right)}}
$$

The chlorophyll within this layer is assumed to be redistributed evenly after the storm and is given by:

$$
C_{0}^{\prime}=\frac{1}{D_{\mathrm{a}}} \int_{0}^{D_{\mathrm{a}}} C(z) \mathrm{d} z
$$


The ratio of the surface chlorophyll concentration after the storm to that before the storm is:

$$
E=\frac{C_{0}^{\prime}}{C_{0}}=a+\sqrt{\frac{\pi}{2}} \frac{a \rho \sigma}{D_{a}}\left[\operatorname{Erf}\left(\frac{z_{\mathrm{m}}}{\sqrt{2} \sigma}\right)-\operatorname{Erf}\left(\frac{z_{\mathrm{m}}-D_{\mathrm{a}}}{\sqrt{2} \sigma}\right)\right]
$$

where $\operatorname{Erf}(\mathrm{x})$ is the error function. $E$ can be expressed as a function of biological parameters and the final mixed-layer depth, $D_{\mathrm{a}}$. As an example, we use the vertical profile for Region 9 in Platt et al. (1991) and compute $E$ as a function of $D_{\text {a }}$ for summer, autumn and spring (Fig. 16). For each season, there exists an optimum MLD which gives the maximum $E$. This is because a small $D_{\text {a }}$ cannot entrain chlorophyll at depth to the mixed layer, and a large $D_{a}$ dilutes the chlorophyll. The optimum $D_{\mathrm{a}}$ falls between $z_{\mathrm{m}}$ and $z_{\mathrm{m}}$ $+2 \sigma$. Fig. 16 shows $D_{a}=$ summer and autumn, respectively. The corresponding values of $E$ are 1.78 (spring), 4.17 (summer) and 10.4 (autumn). These results are consistent with the seasonal variation of maximum $\Delta c h l$ and the corresponding MLD from the numerical model (Fig. 13). Since the MLD increases with the intensity of the storm (Fig. 12), Fig. 16 suggests that a relatively weak storm in autumn can cause a greater increase in surface chlorophyll than a stronger storm in summer. The concept of optimum $D_{\text {a }}$ can also be used to explain the band structure in Figs. 6, $7 \&$ \& 10-13. Across the storm track, the maximum chlorophyll concentration is not around the storm centre but at a distance where the final mixed layer depth is between $z_{\mathrm{m}}$ and $z_{\mathrm{m}}+2 \sigma$.

Data that can be used to compare the model results are scarce, because of the difficulty of collecting surface and sub-surface data during and immediately

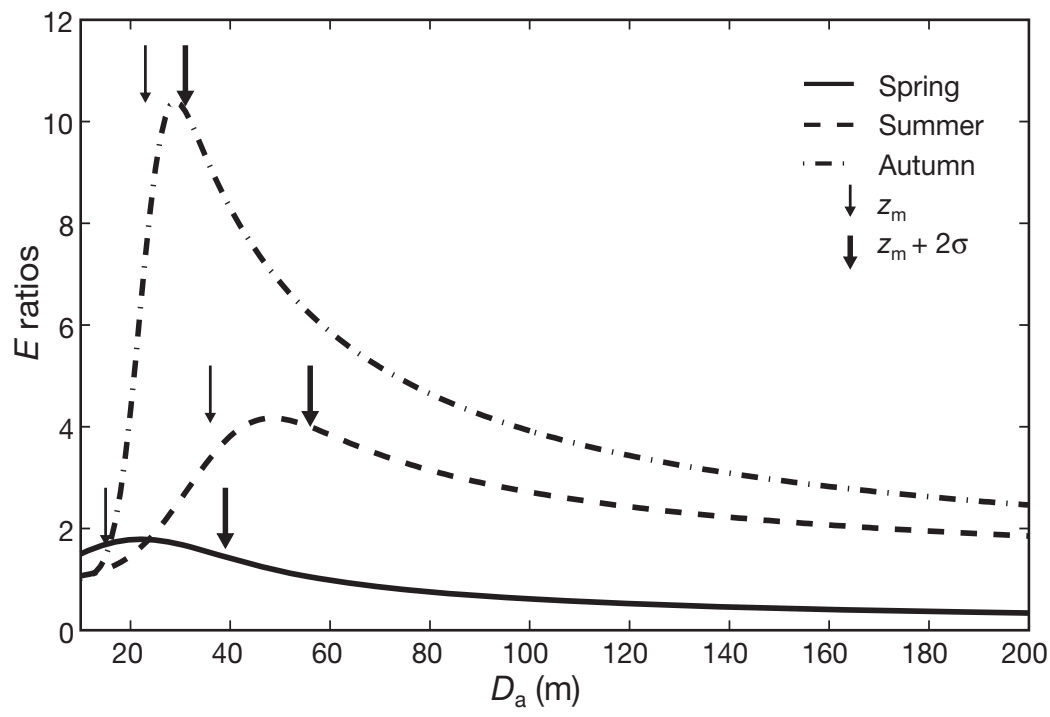

Fig. 16. Surface chlorophyll concentration ratio post-storm:pre-storm $(E)$ as a function of the base of the mixed layer post-storm $\left(D_{\mathrm{a}}\right)$ for spring, summer and autumn after a storm. However, available remotely sensed data are consistent with our model predictions. Hurricane Kate passed the southern Labrador Sea on October 4, 2003. From an analysis of ocean color data, Platt et al. (2005) found the surface chlorophyll increased 3- to 6-fold $14 \mathrm{~d}$ after passage of the hurricane. The increase on the right side of the hurricane path was greater than the increase on the left side. The model results for autumn (Fig. 13) indicate a maximum increase of 10 times and an average (across the storm) increase of 5 times the pre-storm value (Fig. 3). Fig. 13 also shows that the increase is greater on the right side of the storm path. To investigate the impact of storms on time scales longer than a few days, simulation models that input realistic winds and includes all the important biological processes are required.

\section{CONCLUSIONS}

The vertical redistribution of chlorophyll in response to a moving storm has been investigated numerically using an idealized moving storm and initial chlorophyll fields. The suite of numerical experiments includes a control run and 9 sensitivity runs. The results are summarized as follows.

In the area covered by the storm, the surface chlorophyll increases from its initial value after the passage of the storm, except in the shelf regions and in spring. The mixed layer deepens and sea surface temperature decreases primarily as a result of vertical mixing. The change in chlorophyll concentration across the storm track is characterized by a peak on each side of the track. The location of the peak is directly related to the final mixed layer depth, MLD. The change in the MLD and sea surface temperature, on the other hand, has a maximum close to the storm center.

The major factors controlling the change in surface chlorophyll are the initial chlorophyll distribution and the intensity of vertical mixing induced by the storm, specifically, the relative depth of peak concentration $z_{\mathrm{m}}$, versus the final mixed layer depth. If the MLD is shallower than $Z_{\mathrm{m}}$, the surface chlorophyll increases with increasing MLD. If the MLD is deeper than $z_{\mathrm{m}}+2 \sigma$, the surface chlorophyll decreases with increasing MLD. In the reference run (summer conditions), the surface chlorophyll concentration increases 1 to 3 times relative its initial value of $1.0 \mathrm{mg} \mathrm{m} \mathrm{m}^{-3}$. The maximum increase is 
about $3.2 \mathrm{mg} \mathrm{m}^{-3}$, which occurs at about $160 \mathrm{~km}$ from the storm track, where the MLD is about $45 \mathrm{~m}$.

In contrast to the response in the open ocean, where the change in surface chlorophyll is large (except in spring), the surface chlorophyll changes little after the passage of the storm in the shelf regions off the Labrador and west Greenland coast. The different response of the open ocean and the shelf is shown to be caused by upwelling of the subsurface water on the shelf. As a result of upwelling, the high-chlorophyll surface water is replaced by low-chlorophyll water below the mixed layer

For a given chlorophyll distribution, the change in surface concentration is sensitive to the translation speed, size and intensity of the storm. The surface concentration increases with the translation speed and decreases with the size and intensity in the area between the 2 peaks. The change with the storm parameters is the opposite in the area outside the peaks. The maximum, however, changes little with the storm parameters.

The chlorophyll response is strongly dependent on the seasonal variation of the initial chlorophyll fields. The storm has no effect on surface chlorophyll in winter because the initial chlorophyll distribution is uniform. In spring, surface chlorophyll in much of area under the storm decreases after the storm. Summer and autumn have the largest response. The maximum increase in surface chlorophyll concentration is $3.0 \mathrm{mg}$ $\mathrm{m}^{-3}$ for summer and $4.9 \mathrm{mg} \mathrm{m}^{-3}$ for autumn.

Nitrate brought from deep reservoir to the mixed layer by the storm is estimated from a simple 2-layer nitrate model. For a typical storm in summer, about $3.35 \times 10^{3} \mathrm{~mol}$ of new nitrate is added to the mixed layer for each $\mathrm{km}$ that the storm travels. This quantity decreases with the translation speed, and increases with the size and intensity of the storm. The influx of new nitrate will also promote a change in chlorophyll through primary production, but this effect is outside the scope of this paper.

Acknowledgements. The research was supported by the Canadian Space Agency under the Ocean's Pulse (TOP) project and Program for Energy Research and Development (PERD). The authors thank D. Brickman and C. Fuentes-Yaco for reading an early version of the manuscript and giving helpful comments.

\section{LITERATURE CITED}

Babin SM, Carton JC, Dickey TD, Wiggert JD (2004) Satellite evidence of hurricane-induced phytoplankton blooms in

Editorial responsibility: Howard Browman (Associate Editorin-Chief), Storebø, Norway an oceanic desert. J Geophys Res 109: C03043, doi: 10.1029/2003JC001938

Chang SW, Anthes R (1978) Numerical simulation of the ocean's nonlinear, baroclinic response to translating hurricanes. J Phys Oceanogr 8:468-480.

Davis A, Yan XH (2004) Hurricane forcing on chlorophyll-a concentration off the northeast coast of the U.S. Geophys Res Lett 31: L17304, doi: 1029/2004GL020668

Fennel W, Neumann T (2004) Introduction to the modeling of marine ecosystems. Elsevier, Amsterdam

Fuentes-Yaco C, Devred E, Sathyendranath S, Platt T (2005) Variations in surface temperature and phytoplankton biomass fields after the passage of Hurricane Fabian in the Western North Atlantic. Optics \& Photonics. Proc International Society for Optical Engineering. San Diego, CA

Lewis MR, Harrison WG, Oakey NS, Hebert D, Platt T (1986) Vertical nitrate fluxes in the oligotrophic ocean. Science 234:870-873

Mellor GL, Blumberg AF (2004) Wave breaking and ocean surface layer thermal response. J Phys Oceanogr 34: 693-698

Mellor GL, Hakkinen S, Ezer T, Patchen R (2002) A generalization of a sigma coordinate ocean model and an intercomparison of model vertical grids. In: Pinardi N, Woods JD (eds) Ocean forecasting: conceptual basis and applications. Springer, New York, p 55-72

O'Brien JJ, Reid RO (1967) The non-linear response of a 2layer, baroclinic ocean to a stationary, axially-symmetric hurricane: Part I. Upwelling induced by momentum transfer. J Atmos Sci 24:197-207

Platt T, Caverhill CM, Sathyendranath S (1991) Basin-scale estimates of oceanic primary production by remote sensing: the north Atlantic. J Geophys Res 96:15147-15159

Platt T, Sathyendranath S, Ulloa O, Harrison WG, Hoepffner N, Goes J (1992) Nutrient control of phytoplankton photosynthesis in the western north-Atlantic. Nature 356: $229-231$

Platt T, Sathyendranath S, Edwards AM, Broomhead DS, Ulloa O (2003) Nitrate supply and demand in the mixed layer of the ocean. Mar Ecol Prog Ser 254:3-9

Platt T, Bouman H, Devred E, Fuentes-Yaco C, Sathyendranath S (2005) Physical forcing and phytoplankton distributions. Sci Mar 69:55-73

Price JF (1981) Upper ocean response to a hurricane. J Phys Oceanogr 11:153-175

Price JF (1983) Internal wave wake of a moving storm. Part I: scales, energy budget and observations. J Phys Oceanogr 13:949-965

Son S, Platt T, Sathyendranath S, Lee D (2006) Satellite observation of biomass and nutrients increase induced by Typhoon Megi in the Japan / East Sea (JES). Geophys Res Lett 33: L05607, doi: 10.1029/2005GL025065

Tang CL, Wang CK (1996) A gridded data set of temperature and salinity for the northwest Atlantic Ocean. Can Data Report of Hydrographical Ocean Science, 148

Tang CL, Gui Q, DeTracey BM (1998) Barotropic response of the Labrador/Newfoundland shelf to a moving storm. J Phys Oceanogr 28:1152-1172

Yao T, Tang CL, Peterson IK (2000) Modeling the seasonal variation of sea ice in the Labrador Sea with a coupled multicategory ice model and the Princeton ocean model. J Geophys Res 105: 1153-1166

Submitted: May 24, 2006; Accepted: September 10, 2006 Proofs received from author(s): April 2, 2007 